\title{
Editorial for EAIT 2016, Issue 6
}

\author{
Arthur Tatnall ${ }^{1}$
}

Published online: 11 August 2016

(C) Springer Science+Business Media New York 2016

The journal of Education and Information Technologies (EAIT) currently has a couple of Special Issues on the go to which you may wish to make a contribution:

- Creative Online Collaboration in Higher-Education Co-creation (Guest Edited by: Joachim K. Rennstich, Emilija Stojmenova and Björn Stockleben).

- Students, Computers, and Learning: Where is the Connection? (Guest Edited by: Chenglie $\mathrm{Hu})$.

Details and Call for Papers can be found on the EAIT website (http://www.springer. com/computer/general+issues/journal/10639) and I encourage you to consider making a submission.

If you, or one of your colleagues, would like to offer a Special Edition of your own choosing, please send details to me (Arthur.Tatnall@vu.edu.au) so we can discuss this.

To begin this sixth issue for 2016 Erik Blair, Chris Maharaj and Simone Primus (The University of the West Indies, Trinidad and Tobago) write on: "Performance and perception in the flipped classroom". They begin by pointing out that in a flipped classroom where content is delivered outside class through media such as video and podcast, while engagement with the content occurs in class through problem-solving or group work. Their reported study involved an undergraduate course at The University of the West Indies which was taught in both traditional and flipped formats over two successive years. They found that the flipped format led to a slight improvement in how students perceived the course, but with no significant change in exam performance. They recommend that those considering a flipped classroom pay as much attention to student performance as they do to student perception.

"Rethinking online discourse: Improving learning through discussions in the online classroom" was contributed by Cass M. Johnson (University of Cincinnati, USA). This study examined discourse in an online classroom in order to gauge student participation

Arthur Tatnall

Arthur.Tatnall@vu.edu.au

1 Victoria University, PO Box 14428, Melbourne 8001, Australia 
by observing student-to-student and student-to-instructor exchanges within the discussion board. Classroom discourse was analysed using Stahl's computer supported collaborative learning methodology. The study showed that students within the online classroom were able to construct deeper meanings in classroom dialogues through thoughtful and personal contributions, thereby reaching new understandings through collaborative discussion. The author contends that through insightful planning and guided responses, instructors can manage online classroom discussions to better direct student communications in order to improve collaborative learning and knowledge construction.

The following article: "Investigating the learning challenges presented by digital technologies to the College of Education in Kuwait University" is by Fayiz Aldhafeeri (Kuwait University, Kuwait) and Trevor Male (UCL Institute of Education, London, UK). The authors contend that there is now widespread recognition that digital technologies, particularly portable hand-held devices capable of an Internet connection, present opportunities and challenges to how student learning is organised in schools, colleges and institutions of higher education. Although the availability of such devices, controlled mainly by the student and not the teacher, have the potential to change the traditional dynamics and pedagogical patterns of the learning environment, education institutions typically remain organised around spatial and temporal considerations such as buildings, timetables, calendars and internal structures which are designed to classify and manage students. In the reported study students and teaching staff from the College of Education in the Kuwait University were surveyed in order to assess their capability to use these technologies effectively in support of achieving planned learning.

Nurassyl Kerimbayev (Almaty, Kazakhstan) next writes on: "Virtual learning: Possibilities and Realization". The article considers the impact of using a virtual environment in training at a university, and what outcomes can then be reached. The reported study investigates a virtual environment effect instead of a traditional educational approach, considering digital educational resources and their potential adaptation for a trainee. The training is connected with various human activity spheres including the intellectual, cultural, emotional and social.

The following article concerns a study conducted to investigate the continuation of technology use in science and mathematics teaching by teachers who attended a professional development program in Tanzania between 2010 and 2012. Ayoub Kafyulilo (Dar Es Salaam University College of Education, Tanzania), Petra Fisser (National Institute for Curriculum Development, Enschede, The Netherlands) and Joke Voogt (University of Amsterdam, Windesheim University, Amsterdam, The Netherland) offer an article titled: "Factors affecting teachers' continuation of technology use in teaching". They suggest that continuation of technology use is affected by the professional development program and by personal, institutional and technological factors. Findings showed that while all teachers reported gaining knowledge and skills through the professional development program and were positive about technology use in education, only some teachers continued the use of technology.

"Potential use of Augmented Reality in LIS education" is by Magdalena Wójcik (Jagiellonian University, Kraków, Poland) and considers the use of augmented reality technology in library and information science education, aiming to determine the scope and potential uses of augmented reality in the education of information professionals. The study concluded that augmented reality technology is a useful teaching tool which 
enables students to achieve improved learning outcomes in the practical skills needed by librarians, as well as the personal and social competencies relevant to labour market needs.

"Virtual schools: The changing landscape of K-12 education in the U.S." by Ian N. Toppin (Fort Valley State University, USA) and Sheila M. Toppin (Clark Atlanta University, USA) notes that virtual schools are a growing phenomenon in K-12 education and that school systems in almost every state in the US offer some version of fully online or blended education. This suggests that virtual school enrolments may soon exceed those of traditional brick-and-mortar schools. Their paper examines some of the challenges and strengths of virtual schools and offers questions to consider when deciding whether or not a virtual school option would be an ideal solution.

Pernilla Josefsson, Stefan Hrastinski and Daniel Pargman (KTH Royal Institute of Technology, Stockholm, Sweden) and Teresa C. Pargman (Stockholm University, Sweden) argue that research has shown that students perceive a distinct divide between educational and private use of social media. In their article: "The student, the private and the professional role: Students' social media use" they explore this divide by focusing on master students' perception of roles when using social media. Their qualitative study, comprising of analyses of home exams and interviews, supported previous research suggesting that students perceived a distinct divide between educational and private use of social media. The results also indicate that there is yet another type of use: social media as a tool for career-building purposes (professional use). Implications of social media for use in higher education are described through the analysis of three roles as performed by the individual: the student role in educational settings, the professional role for career-building and the private role.

J. Enrique Hinostroza, Andrea I. Ibieta and Christian Labbé (Universidad de La Frontera, Chile) and Magdalena Claro (Pontificia Universidad Católica de Chile) note that research on teachers' use of ICT has focused mainly on the classroom context and few studies have focused on their use elsewhere. Their article: "Characterisation of teachers' use of computers and Internet inside and outside the classroom: The need to focus on the quality" attempts to fill this gap. It presents a case study of twelve secondary school teachers and investigates their use of ICT inside and outside the classroom. Their results show that teachers use these tools inside the classroom for presentations and support of instructional strategies, and outside the classroom for lesson preparation, administration and communication, as well as design of students' assignments with ICT.

"Research of technical knowledge and creativity development of children in preprimary education through interactive whiteboard" has been contributed by: Peter Brečka and Marcela Červeňanská (Constantine the Philosopher University in Nitra, Slovakia). Their article focuses on the utilisation of interactive whiteboards as didactic technology mediating information through multimedia worksheets applied in education process in pre-primary education. The aim was to determine whether this can significantly increase the children's acquired knowledge in technical skills education and whether it can positively influence development of children's creatively.

The study reported on in the next article designed and tested an intervention with elementary-aged children to promote social and emotional learning around technology. Chuanpob Iaosanurak and Sumalee Chanchalor (King Mongkut's University of Technology Thonburi, Bangkok, Thailand) and Elizabeth Murphy (Memorial University of 
Newfoundland, Canada) have written on: "Social and emotional learning around technology in a cross-cultural, elementary classroom". Their study of five Thai and eighteen Cambodian learners in a Thai elementary classroom considered interventionstructured learning around technology as a catalyst and scaffolding tool that engages learners in cross-cultural, collaborative interaction, dialogue, problem-solving, decision-making and reflection in a face-to-face context.

Next, Muhammad Anshari, Yabit Alas and Lim Sei Guan (Universiti Brunei Darussalam, Brunei) write on: "Developing online learning resources: Big data, social networks, and cloud computing to support pervasive knowledge". They suggest that utilising online learning resources from multiple channels in learning activities promises extended benefits from traditional learning-centred based to a collaborative-based learning-centred one that emphasises pervasive learning anywhere and anytime. They argue that while in conventional learning practices a student is perceived as a recipient of information and knowledge, when big data, cloud computing and the semantic web are combined into online learning this offers a broader spectrum of pervasive knowledge acquisition to enrich users' experience in learning.

In the next article: "VLES, social stories and children with autism: A prototype implementation and evaluation" the authors: C. Volioti1 \& T. Tsiatsos (Aristotle University of Thessaloniki, Greece), Mavropoulou (University of New England, Australia) and C. Karagiannidis (University of Thessaly, Greece) claim that Virtual Learning Environments have been successfully used in educational interventions for children with Autism Spectrum Conditions for overcoming their persistent differences related to social communication and imagination. Their article investigates the potential of Virtual Learning Environments presenting Social Stories as an advantageous pathway for the development of social problem skills in children with Autism Spectrum Conditions.

"Relationship between gender identity, perceived social support for using computers, and computer self-efficacy and value beliefs of undergraduate students" describes research undertaken by: Naraphol Deechuay and Sorakrich Maneewan (King Mongkut's University of Technology Thonburi, Thailand), Ravinder Koul (The Pennsylvania State University, USA) and Thanita Lerdpornkulrat (Srinakharinwirot University, Thailand). Their data was collected from first year undergraduate students, not intending to major in the computer sciences, at a university near Bangkok. Their results showed that parental and peer support for using computers was positively associated with computer self-efficacy and value beliefs for both males and females. Gender role socialisation and expectancy-value theories were used to interpret group differences in computer self-efficacy and value beliefs.

Leslie J. Wardley and Colin F. Mang (Nipissing University School of Business, Canada) then write on: "Student observations: Introducing iPads into university classrooms". Their paper explores the growing trend of using mobile technology in university classrooms. In particular it explores the use of tablets to identify learning benefits gained by students. They argue that students act on their efficacy beliefs to make decisions regarding technology's influence in improving their education. The researchers construct a theoretical model in which internal and external factors which consider a student's self-efficacy which in turn affects the extent of adoption of a device for educational purposes. Through qualitative survey responses of university students who were given an Apple iPad to keep for the duration of a university course they found 
high levels of self-efficacy leading to positive views of the technology's learning enhancement capabilities.

In "Self-regulated learning and the role of ePortfolios in business studies" by Lucía Morales and Valentina Tarkovska (Dublin Institute of Technology, Ireland) and Amparo Soler-Domínguez (Universitat Jaume I, Spain) students' work in ePortfolios was assessed through a case study supported by observation techniques and eQuestionnaires to gather data from a sample of eighty students over a period of four years with the purpose of exploring whether ePortfolios can be used efficiently to support the learning process of postgraduate business students taking a course where finance modules were a major component. Their empirical findings suggest that ePortfolios could be used to facilitate and enhance students' self-regulated learning and that the role of the instructor was found to be fundamental during early stages of the learning process to guide and coach students on how to use the tool.

"A naive bayes approach for converging learning objects with open educational resources" describes how these resources offer digitised material freely available to the students and self-learners. Its authors: A. Sai Sabitha, Deepti Mehrotra and Abhay Bansal (University UP, Noida, India) and B. K. Sharma (NITRA, Ghaziabad, Uttar Pradesh, India) note that many institutions have incorporated these into their higher educational systems to improve the quality of teaching and learning and to promote individualised study and collaborative learning. The authors suggest that localisation of high quality learning materials within the content of Learning Management Systems delivered as a single instructional unit may help in greater knowledge delivery to satisfy the diverse learning needs of students.

The article that follows: " $A$ design science research methodology for developing a computer-aided assessment approach using method marking concept" describes research undertaken by Hussein Genemo, Shah Jahan Miah and Alasdair McAndrew (Victoria University, Australia). The authors begin by describing assessment as an authentic method that plays an important role in evaluating students' learning attitude in acquiring lifelong knowledge, but that traditional methods of assessment including Computer-Aided Assessment for mathematics show limited ability to assess students' full work unless multi-step questions are sub-divided into sub-questions. To address this issue, the aim of their study was to develop a methodological framework to create an ICT artefact prototype.

"Eye tracking system for enhanced learning experiences" is by: R. K. Sungkur, M. A. Antoaroo and A. Beeharry (University of Mauritius, Réduit, Mauritius). They point out that in most learning environments, information is basically available in the form of written text and that eye-tracking technology, eye movements, scanning patterns and pupil diameter are indicators of thought and mental processing involved during visual information extraction. They suggest that learners can be supported and guided throughout their learning journey by real-time information of the precise position of gaze and of pupil diameter. The described research provides an insight into the various existing techniques that contribute to the improvement of the learning mechanism through proposing a real time monitoring system using image processing and eye detection techniques. This is a low cost system compatible with any computer equipped with an ordinary web camera.

Following is an article by Ali Semerci (Ankara, Turkey): "Examining middle school students' views on text bullying”. The reported research examined middle-school 
students' views on text bullying in regard to gender, grade level, reactions to bullying and frequency of internet use. It involved collecting data via questionnaires and a survey from 872 students in schools located in central Ankara and utilised data drawn from the use of mobile phones. The research findings illustrated that male students are significantly more likely to become victims of text bullying compared with female students, yet surprisingly female students displayed bullying behaviours more often than male students. Regarding the reactions of students to bullying, there was no significant relation by gender.

From Japan, Tomoko Kajiyama (Aoyama Gakuin University, Japan) writes an article titled: "An improved botanical search application for middle- and high-school students". He begins by noting that a botanical data retrieval application has been improved to make it better suited for use in middle and high school science classes. He describes the search interface as ring-structured and that it treats multi-faceted metadata intuitively so enabling students not only to search for plant names but also to learn about the morphological features and taxonomy of plants. The effectiveness of the improved application was then evaluated with results showing that students could more easily find plant names by simply rotating the search rings and could more easily analyse the information by quickly recognising the features of retrieved plants.

"The impact of webinar-webcast system on learning performance" is an article by Judit T. Nagy and Mária Bernschütz (Edutus College, Budapest, Hungary). They note that using online video presentations is gaining ground in higher education and discuss the initial results of a longer research project that investigates the effect that the availability of online videos introduced to complement live presentations has on learning performance. The quasi-experimental research covered each college year and each course of the college including the business faculty. Results have shown that the availability of online videos resulted in significant improvement in semester grades and it contributed to reducing dropout rates.

The article that follows: "Blending an Android development course with software engineering concepts" has been contributed by: Alexander Chatzigeorgiou and Stelios Xinogalos (University of Macedonia, Greece), Tryfon L. Theodorou and George E. Violettas (Technical Trainers College, Riyadh, Kingdom of Saudi Arabia). They point out that the tremendous popularity of mobile computing in general, and Android in particular, has attracted millions of developers who see opportunities for building their own start-ups and that as a consequence Computer Science students are expressing an increasing interest in Java-related development for Android applications. Most software engineering courses, however, focus on 'conventional' software development for desktop or web applications and in this article the authors report on the design, implementation and assessment of a novel short course aiming at bridging the gap between software engineering and Android development.

Sarah K. Howard (University of Wollongong, Australia) and Kate Thompson (University of Sydney, Australia) next write on: "Seeing the system: Dynamics and complexity of technology integration in secondary schools". Their paper introduces system dynamics modelling to understand, visualize and explore technology integration in schools through the development of a theoretical model of technology-related change in teachers' practice. They note that technology integration is a dynamic social practice, within the social system of education and that it is difficult, if not nearly impossible, for the human mind to fully conceptualise complex social systems and so it is necessary to 
use conceptual frameworks designed to examine these phenomena. The use of system models can potentially support a shift from focusing on teachers' technology use to student outcomes, and the feedback loop of students' technology use on teachers' practice.

"An empirical investigation of smart board innovations in teaching in UAE University" by Nabeel Al-Qirim (United Arab Emirates University, UAE) describes research that investigates teaching faculty adoption and usage of the Interactive or Smart White Board Technology in UAE University. The developed theoretical framework is based on technological innovation theories and is made up of different socio-technical factors. Contrasting findings pertaining to certain factors across adoption and usage provided both absorbing and challenging insights and implications arising from significant and insignificant factors that lead to a conclusion that this technology is still evolving.

The final article in this issue: "Innovation in services: A lancastrian approach to the field of e-learning" describes research undertaken by: P. Avinash Shivdas (Amrita University, Kerala, India) and Soumya Sivakumar (Marymount University, Arlington, USA). They point out that innovation in services is one of the prime drivers of economies and that various schools of thought have emerged over the past few decades in this area. Their article focuses on the evolution of the 'synthesis' school of thought and contributes to literature by extending the framework proposed by Lancaster and other researchers by incorporating aspects of Web 2.0 technology with a specific reference to e-learning.

The 26 articles in this issue have come from the following countries: Trinidad and Tobago, USA, Kuwait, UK, Kazakhstan, Tanzania, The Netherlands, Poland, Sweden, Chile, Slovakia, Thailand, Canada, Brunei, Greece, Australia, Ireland, Spain, India, Mauritius, Turkey, Japan, Hungary, Saudi Arabia and United Arab Emirates.

\section{Arthur Tatnall \\ EAIT Editor-in-Chief}

